\title{
5S IMPLEMENTATION AND ITS EFFECT ON PHYSICAL WORKLOAD
}

\author{
Ayush Khandelwal ${ }^{1}$, Prathik R. ${ }^{2}$, Rahul P. Kikani ${ }^{3}$, Vigneshwaran Ramesh ${ }^{4}$ \\ ${ }^{\text {I}}$ Student, Department of Mechanical Engineering, Amrita School of Engineering, Amrita Vishwa Vidyapeetham, \\ Coimbatore, Tamil Nadu, India \\ ${ }^{2}$ Student, Department of Mechanical Engineering, Amrita School of Engineering, Amrita Vishwa Vidyapeetham, \\ Coimbatore, Tamil Nadu, India \\ ${ }^{3}$ Student, Department of Mechanical Engineering, Amrita School of Engineering, Amrita Vishwa Vidyapeetham, \\ Coimbatore, Tamil Nadu, India \\ ${ }^{4}$ Student, Department of Mechanical Engineering, Amrita School of Engineering, Amrita Vishwa Vidyapeetham, \\ Coimbatore, Tamil Nadu, India
}

\begin{abstract}
This article presents a case study on the implementation of the $5 S$ methodology. Analysis of time and energy expenditure of two subjects in a paper conversion machinery manufacturing plant was carried out before and after the implementation. Two subjects were chosen for the analysis. A device which measures physical energy expenditure helped evaluate the effectiveness of this methodology. Initially the subjects perceived the work to be physically stressful and the morale of the workplace was low. The study indicated that the time consumed and energy expenditure was drastically reduced after the implementation of this methodology, which in turn had a positive effect on productivity.
\end{abstract}

Keywords: 5S methodology, Lean Tools, Time Study, Energy Analysis

\section{INTRODUCTION}

The paper conversion machinery industry demands a wide variety of models and variants. Manufacturers thus compete by offering customized solutions to clients. To offer highly customized solutions to clients, manufacturers are required to handle large number of components en route to completing the manufacturing process. Cogent handling of the components during the process is essential to productivity. An organizational methodology like $5 \mathrm{~S}$ needs to be used which reduces the waste of resources and space while increasing operational efficiency. Many companies use this technique in their efforts to achieve a lean process.

Traditionally time is considered an important factor for productivity. Solutions are given keeping in mind the need to save on time. Another approach would be to consider the effect of physical workload on productivity. Time and energy need to be managed synchronously to achieve optimal productivity. Manual material handling involves continuous and repetitive movements, which result in fatigue over a period of time. It is essential to gain knowledge on the physical workload and its effect on productivity.

This paper presents a case study carried out in a paper conversion machinery manufacturing plant where time and energy analysis was carried out before and after the implementation of a workplace organization methodology. The aim of the study was to implement $5 \mathrm{~S}$ and evaluate its effect on productivity in terms of time and energy expenditure.

\section{LITERATURE REVIEW}

A good organisational methodology like $5 \mathrm{~S}$ is an efficient lean manufacturing tool. Bayo A.M. explored the relationship between $5 \mathrm{~S}$ use, contextual factors and performance .The contextual factors include structural features of the firm, environment, human resources and quality management. The performance refer to improvements in productivity, quality etc. [1]. Ho. believes that the key to productivity and quality is to carry out regular audits which constantly adapt to the changing business environment [2]. He also demonstrates the correlation between $5 \mathrm{~S}$ and Total quality management which further indicates the importance of $5 \mathrm{~S}$ for a sound approach towards TQM [3]. Moradi's findings show the effect of 5S implementation on TQM in a factory in Iran [4]. Hamzah believes that if $5 \mathrm{~S}$ is implemented successfully majority of the recurrent problems would be solved [5]. Ansari presented the benefits of $5 \mathrm{~S}$ in maintaining safety standards, a significant decrease in number of injuries were observed after the implementation of this technique [6]. Nilipour shows the importance of $5 \mathrm{~S}$ in lean manufacturing in the form of a tool which helped to reduce waste and decrease time spent on non-value added activities [7]. A great amount of emphasis is given on training, for effective implementation training employees to sustain this technique is the key [8].

\section{PROBLEM STATEMENT}

The case study was carried out at a paper conversion machinery manufacturing plant. The manufacturer provides a wide variety of advanced paper conversion machinery along with several customizing options. This involves a large 
number of different components. The management perceived the morale of the shop floor workers to be below usual standards. An Oral discussion was carried out with the shop floor workers, asking them about the different problems they face. The problems faced by them were taken into account, as our primary focus is on improving the productivity of the manufacturing plant, the problems which largely influenced it were taken into consideration.

\subsection{Study Group}

Two highly skilled workers were chosen for the analysis. Both the workers, subject (1) and subject (2) were male, 38 and 34 years old respectively. Subject (1) is a lathe operator and Subject (2) is involved in the assembly process.

\subsubsection{Subject (1)}

The lathe operator, during the tool changing operation finds it difficult to search for the required tool in the toolbox since the storage is not organized. This results in a waste of time and energy. Time and energy is also wasted while looking for the next component to be machined because the components are kept in a highly disorganized manner on the shop floor. After the part is machined in the lathe, the operator has to transport the component to a storage which is not easily accessible by him.

\subsubsection{Subject (2)}

This assembly specialist feels that the various parts manufactured in house, that are that are to be assembled, are placed around the assembly area on the floor, so he has to search for the part required at every stage from a pile of parts. The subject has to lift the parts required for assembly from the floor onto the assembly table. He finds it difficult to handle heavy parts and sometimes requires the assistance of his fellow operators, which in turn interrupts them from doing their job efficiently. The parts that are outsourced by the company are placed around the assembly area in boxes. The subject has to search from multiple packages until he finds the part he desires. Fasteners like screws, nuts and bolts of multiple sizes are placed in a common box on the assembly table. This requires him to search inside the box to find the exact fastener he requires for the particular assembly operation.

\section{TOOL/METHODOLOGY USED}

There are a number of tools that are used in lean manufacturing to improve the productivity and efficiency of an organization. Some of the widely used tools are 5S, Kaizen, Jidoko, Total Productive Maintenance etc. Considering the problems currently faced by the industry under study, the tool adopted was 5S Methodology. This technique was used to arrive at solutions to the various problems encountered by the subjects. Mainly the time and the energy consumed before and after the implementation were compared.

\subsection{Tool used for Analysis}

The energy expenditure of the subjects was calculated with the help of a device called IDEEA - Intelligent Device for Energy Expenditure and Physical Activity. This microprocessor-based device provides detailed information on type, duration, frequency and intensity of various physical activities and their corresponding energy expenditure estimates.

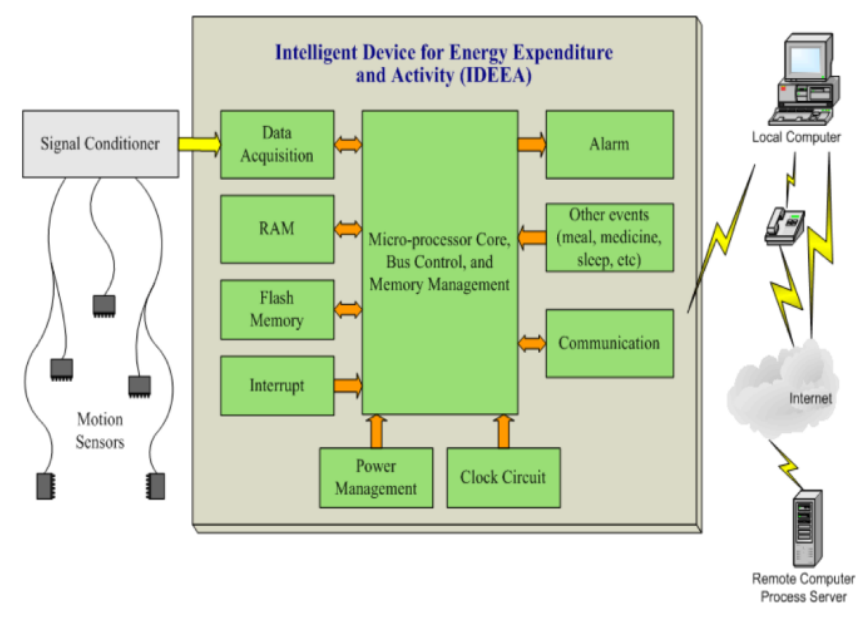

Fig -1: Schematic of the working of IDEEA

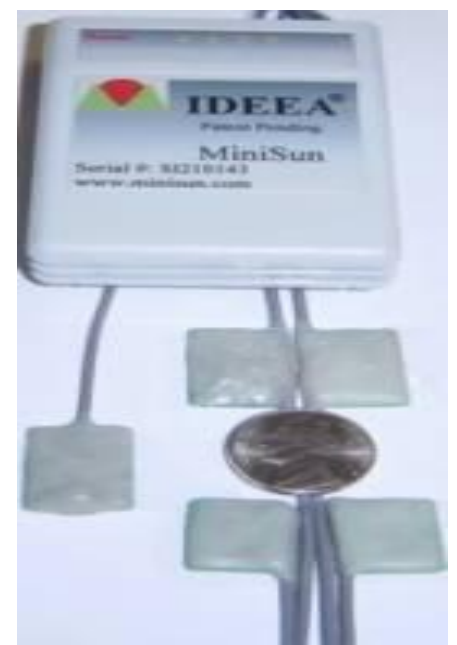

Fig -2: IDEEA device

\subsection{Analysis of Subject (1)}

A series of changes were made to save time and energy for Subject (1). Emphasis was laid on three of the five principles namely Sort, Set in order and Shine. A tool rack or tool stand was created and placed next to the operator with name tags on each tool. This enabled him to find the required tool quickly and efficiently, while saving time and energy. The various parts to be machined were placed neatly and in an organized manner in a large shelf. This made sure that the operator wastes minimum time and energy looking for the next part to be machined. A large trolley with customised organisational facilities was placed near the operator to store recentely machined parts and were later moved to the storage shelf. 


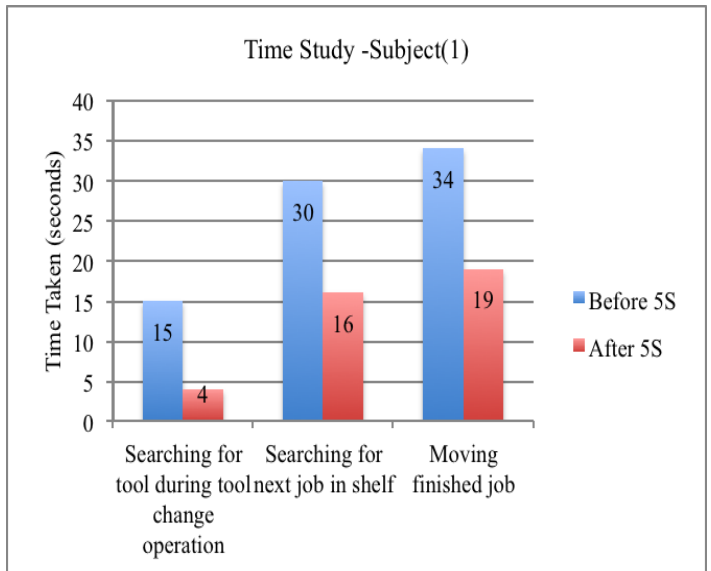

Chart -1: Time study for subject (1)

Chart -1 shows the time taken by subject (1) during various activities carried out as a part of the manufacturing process. Once the changes were made the time study was repeated and the comparison is shown in the chart above.

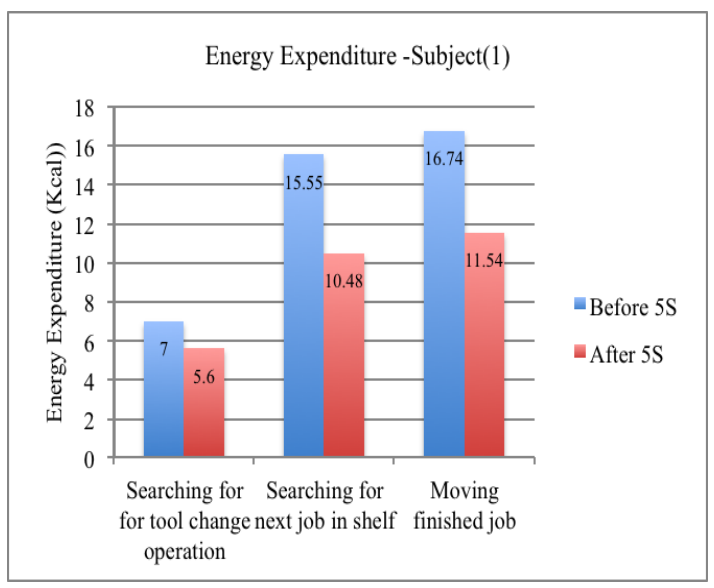

Chart -2: Energy Expenditure for subject (1)

Chart -2 shows the difference in energy expenditure before and after implementation of $5 \mathrm{~S}$ methodology.

\subsection{Analysis of Subject (2):}

The 5S methodology was implemented in the assembly area and an analysis was carried out on Subject (2). Primary focus was to practice Sort, Set in order, Shine and Standardize. All the machined components were placed in storage racks near the assembly area, in an organized manner. The assembly operator was able find the desired component quickly and easily. The parts required for assembly were taken from the storage rack and placed in a trolley which is almost the same height as the assembly table. The heavier parts were easy to handle now. The parts that were outsourced were taken out from their respective packaging and segregated based on their type of material, size, requirement etc. and stored in shelves so that they are easily accessible. The fasteners based on their size, shape and, type were segregated into various boxes so that the operator does not waste much time or energy in looking for them.

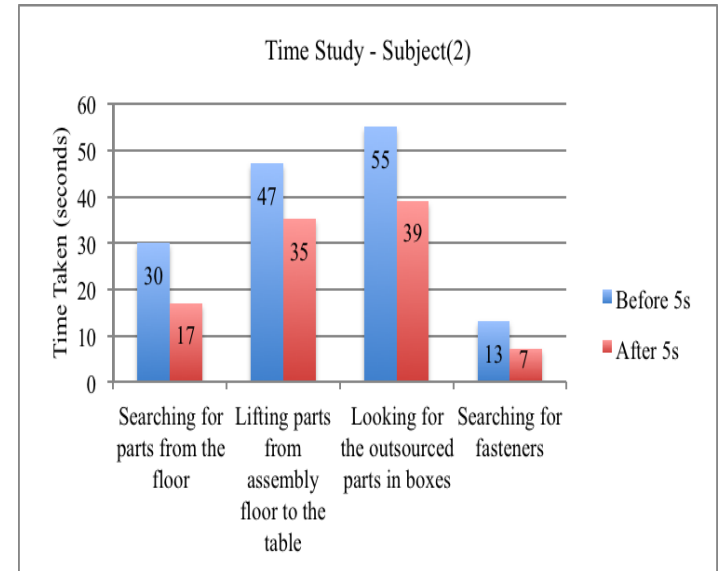

Chart -3: Time study for subject (2)

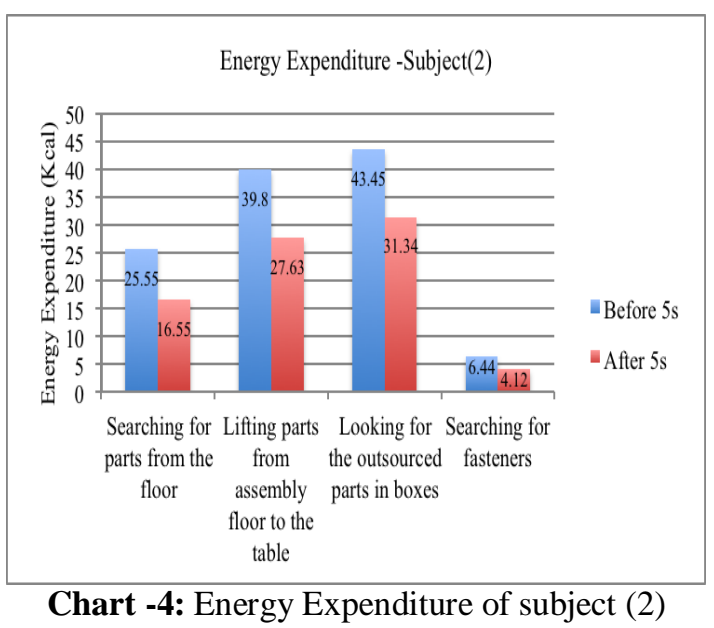

Charts -3, 4 show the reduction in time consumption and energy expenditure for the tasks carried out by Subject (2).

\section{RESULTS AND DISCUSSION}

The analysis of the time consumed and energy expenditure for both the subjects after implementing the $5 \mathrm{~S}$ organisational methodology clearly shows that this tool has potential to deliver a positive impact on productivity. The results of the time study show that proper organisation and efficient material handling saves a considerable amount of time. The results of the energy analysis indicates to us that for a given work 5S methodology plays a vital role in saving energy, that is, after its implementation the energy required to carry out a particular activity would be less than the energy consumed before adopting $5 \mathrm{~S}$. The morale of the workers has been bolstered after the changes have been made, which certainly is a major factor for improvement in productivity.

Table 1: Summary of results

\begin{tabular}{|l|l|l|}
\hline Subject (1) and (2) & Before 5S & After 5S \\
\hline Total Time (seconds) & 224 & 137 \\
\hline Energy Expenditure (Kcal) & 154.53 & 107.28 \\
\hline
\end{tabular}


Table 2: Savings in terms of time and energy expenditure

\begin{tabular}{|l|l|l|}
\hline Subject & Time Saved & Energy Saved \\
\hline Subject (1) & $50.63 \%$ & $29.70 \%$ \\
\hline Subject (2) & $32.41 \%$ & $30.87 \%$ \\
\hline
\end{tabular}

\section{FUTURE SCOPE}

This experiment clearly demonstrates that by having an efficient organisational method in material handling, we can significantly improve productivity. Two subjects were considered for this analysis and 5S was implemented in their work areas and positive results were obtained with the existing limitations in the shop floor. Making Changes in the overall layout of the shop floor and implementing a proper organisational method like $5 \mathrm{~S}$ across the entire the plant can drastically improve productivity.

\section{REFERENCES}

[1]. Bayo. A.M,, Pintado A.B., and Cerio J M.D., $5 S$ use in manufacturing plants: contextual factors and impact on operating performance, International Journal of Quality \& Reliability Management, 27 (2), pp.217 - 230, 2010.

[2]. Ho. S.K.M., 5S practice: a new tool for industrial management, Industrial Management \& Data Systems, 98(2): p. 55-62, 1998.

[3]. Ho. S.K., Cicmil. S., and Fung C.K., The Japanese 5-S practice and TQM training. Training for Quality, 3(4), pp. 19-24, 1995.

[4]. Moradi. M., Abdollahzadeh M., and Vakili. A., Effects of implementing 5S on Total Productive Maintenance: A case in Iran. 2011: IEEE.

[5]. Hamzah. A., and Ho.S., TQM training for small and medium industries in Malaysia, Training for Quality, 2(2), pp. 27-35, 1994.

[6]. Ansari. A., and Modarress. B., World-class strategies for safety: a Boeing approach, International Journal of Operations \& Production Management, 17(4), pp. 389-398, 1997.

[7]. Nilipour. A., and Jamshidian. M., 5S as an Environmental Organization Management Tool; Benefits and Barriers. International Management Conference, 2005.

[8]. Ho. S.K.M., Japanese 5-S - where TQM begins, The TQM Magazine, 11(5), pp. 311-321, 1999.

\section{BIOGRAPHIES}

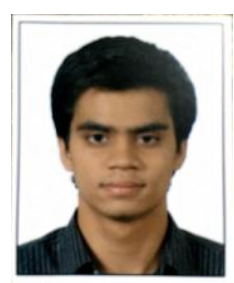

Ayush Khandelwal is a final year mechanical engineering student. $\mathrm{He}$ is pursuing his B.Tech from Amrita Vishwa Vidyapeetham, India.

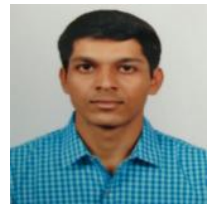

Prathik R. is a final year mechanical engineering student. $\mathrm{He}$ is pursuing his B.Tech from Amrita Vishwa Vidyapeetham, India

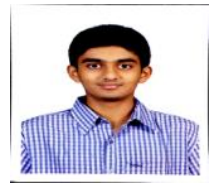

Rahul P. Kikani is a final year mechanical engineering student. $\mathrm{He}$ is pursuing his B.Tech from Amrita Vishwa Vidyapeetham, India.

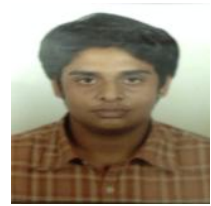

Vigneshwaran Ramesh is a final year mechanical engineering student. $\mathrm{He}$ is pursuing his B.Tech from Amrita Vishwa Vidyapeetham, India 